\title{
Sector Policy for Health and Medical Spa Tourism in Republic of Bulgaria
}

\author{
Dessislava Alexova (Corresponding author) \\ International Business School \\ 14 Gurko Str., 2140, Botevgrad, Bulgaria \\ Tel: 359-886-347-274Ｅ-mail: aleksova.desislava@acad.ibsedu.bg
}

\author{
Jordan Jordanov \\ Faculty of Business Management, University of Forestry \\ 10 Kliment Ohridsky Blvd., Sofia 1756, Bulgaria \\ Tel: 359-877-434-574Ｅ-mail: jordanjordanov@mail.bg
}

Received: August 4, 2013 Accepted: September 5, 2013 Published: December 5, 2013

doi:10.5296/bms.v4i2.4675 URL: http://dx.doi.org/10.5296/bms.v4i2.4675

\begin{abstract}
The present study examines the specifics of the Health and Medical Spa tourism and the opportunities for its priority development according to the European and global trends, strategic development and the mechanisms of the regional sector policy. It is analyzed the tourist supply, the tourists profile as well as the characteristics of the specialized health and medical Spa programmes. It is accomplished critical analysis of the basic world and European priorities and perspectives, based on macro economical factors and premises. The organizational and managerial stresses of the sector policy for priority development of the Health and Medical Spa tourism in Bulgaria in the frames of "the Strategy - Bulgaria 2010", based on researches of world organizations, statistical data and analyses of information, gathered by authors of specialized researches at international forums and meetings, and the underlying conclusions and recommendations are summarized.
\end{abstract}

Keywords: Health tourism, Medical SPA tourism, Sector policy, Specialized tourism programmes, Healthy living environment, Regional policy 


\section{Introduction}

The growing needs of prophylaxis, treatment and rehabilitation of the socially significant diseases of our citizens as well as the mass diseases and the aging of the population in Bulgaria and in the European Union (the number of the pensioners in the EU is $17 \%$ of the total population and grows up with 40 million persons annually) orientates the debate towards the priority development of the Health and Medical Spa (domestic and international) tourism, to conduction of new long-term and coordinated state policy. The process associated with the growing popularity of the environmentally friendly and healthy lifestyle for millions of domestic and foreign tourists as well as to the aging tendencies of the Bulgarian and European population. This brings out at foreground the serious need of change of the state and local investment, economic, social and human resources policy in medium and mainly long-term plan. The change at product level is associated with support of the development of the most promising forms and profiles of market-selected local programmes for domestic and international Health and Medical Spa tourism.

\section{Features of the Health and Medical Spa tourism}

At its core the Health tourism represents travel and stay of people in order to maintain, stabilize and recover of the physical, intellectual and social well-being through use of specific health services at a location other than permanent residence and place of work (Kaspar, 1995). The World Association of Medical Tourism defines the concept "medical tourism" as „travelling people, living in one country to another country to obtain therapeutically, dental or surgical service, which is also equivalent to or better than the same service in their own country and travel for medical care because of price advantage, easier access and higher quality of the service. The International Spa Association (ISPA) itself defines "SPA" as visit and stay in tourist establishment with presence of healthy water resources or places devoted to overall well-being through a variety of professional services, which contributes to the recovery of the intellectual and physical strengths of the person".

The modern medical SPA tourism itself could be defined as sector of the health tourism, which focuses on the health prevention and the recreational influence of the natural resources and factors over the human organism incl. relief climate waters, biodiversity, ecological foods etc. At its core, the services package medical Spa focuses on health prevention and emphasizes on the recreational influence of the natural resources and factors on the human organism. The whole range of programmes, tourist packages and groups of services is dedicated to this profile of specialized services, offered at different sites in "urban environment", in the frames of the "leisure industry" and the tourist service as independent factors in the field of the services. For the last 20-30 years the specialized tourist packages for Medical Spa tourism are arranged by tour operators as well as by services providers in various curative-recreational or prophylactic programmes, tailored to maximize the effective demand of the consumers in urban and resort environment. This integrated assortment list spreads and develops as a result of the product and technology innovations and solutions, financed and implemented in newly built facilities around the world by new and more 
perspicacious investors and entrepreneurs. The scientific-applied studies mark out the outline of the health profile of services within the "leisure industry" and tourism. This process which started as mode of satisfaction of the needs of health care to the "urban consumers" transferred the Spa medical services and programmes into self-developing specialized form of contemporary tourist service.

The travel motivation aimed at health or Spa tourism for each healthy or diseased person is formulated or caused by different specific personal considerations and reasons and causes. The length of stay, the treatment value or the recovery, are in direct relation to the type and the extent of the disease and the recognized need for prevention of the modern diseases. In the same time there is existing report on the age and social status of the tourist. Regarding the health prevention tourism - the prevailing group are mainly younger as well as in active working age individuals, which inhabit the urban areas. They are looking for forms of recreation through active leisure and psychological and physical relaxation as well as through prophylactic programmes, using the means and methods of the physical medicine. This content of the motivation for tourist trip forms the essence of the medical Spa range of preventive and recreational programmes and services, offered by the profiled tourist enterprises and their establishments working in a market environment.

\section{Premises and Trends of Development in Health and Medical Spa Tourism}

The early twentieth century was a period of enforced globalization in various regions of the world as well as of processes of active urbanization and annually concentration of million people in so called "urban areas", in search of more profitable job and a better life. This migration of human flows to more industrial, social and standard of living developed urban centers were caused by the growing socio-economical problems of residents outside these areas. However, the urban environment removes the people from the nature and deprives them of its overall positive impact, including and on their health. This leads to generally negative impact on the health status of the population, mostly of the people exposed to the influence of harmful factors as stress, immobilization, improper nutrition, chronic mental and physical fatigue, etc.

There is a significant growth of mass health diseases and trends as a result of worsen ecological and vital environment, through the city inhabitants in the industrially developed countries, which outlines health problems of great social importance. The marketing demand of solutions of the health problems of the urban areas inhabitants' provokes and motivates the rapid development of different forms of specialized tourist services as proposal of oncoming groups of product lines. In Europe and worldwide increases the importance of the healthy style of living. This way or concept of living is an integral part of the contemporary system of values of the people in developed countries, which increasingly reflects the attitude and the concern for the personal health and includes a selection of programmes for increased vital activity and forms of mental, physical and emotional recovery of the health status of contemporary people, mostly of the urban and industrial areas and territories. 


\section{Ml Macrothink}

The number of representatives of different age and social groups in the developed countries marks a significant growth on the base of promotion of environmentally lifestyle as main value and emphasis of a new health culture. They strive for sustain of good physical condition combined with initiatives directed to spiritual enrichment and growth. One of the positive facts is the growing concern of many of the employers, reconsidering the need to provide healthy and safe work conditions and active leisure to their employees. The demographic processes in most EU member states imposed new economic motivation for investors and entrepreneurs, inducing them to provide funds for prophylaxis and sustain of the psycho-physical and emotional strengths of their employees. This complex of conditions and processes is becoming a major factor in the development of specialized types of services offered in urban and resort environment within the programmes for health and medical Spa tourism.

The market segmentation formed two trends for specialized tourist service, which are relevant to the chronically diseased customers of health (medical, spa, etc.) tourist services and clinically healthy tourists looking for prophylactic and relax in the form of services as tourist trips directed to recreation and psychological and physical recovery in pure natural environment.

In this context - the programmes offered by specialized tour operators, hospitals and tourist complexes profiled in this sphere, which provide and distribute different health and Spa services, offer various therapeutic and rehabilitative programmes, directed to people with diagnoses stated by specialists or with proven chronicle diseases.

The programmes as well as the tourist packages for the clinically healthy people of different ages are elaborated and proposed as by specialized tour operators as by Spa and wellness tourist establishments in urban and resort environment.

The expected trends of the tourist behavior globally by 2020, which shall an impact in the process of formation and supply of health tourism in Bulgaria, including Medical Spa tourist product are reduced to the following:

Increase regarding the requirements of the tourists to the quality, specificity attractiveness and diversity of the tourist services as main factor for the formation of the tourists' behavior;

- Targeting the preferences of the tourists from one country to destinations and countries, which could guarantee safety and tranquility from one hand and from other hand to the specific tourist forms - Spa and wellness, hobby and extreme experiences, ecological and agricultural tourism, sports, adventures, etc.;

- Increase of the number of the elderly tourists, which purpose of travel and stay is medical treatment, prophylaxis, rehabilitation and recovery;

- Expansion of the practice of double use of annual leave as well as increase of the share of vacations outside the high summer season; 
- Adaptation of the tourist product in accordance with changes in the way of work, the social life, the behavior, expectations and preferences of the tourists. The reorientation from "economy of the services" to economy of experiences" highlights the tourist attractions, animation and supply of national tourist specifics. The emphasis is placed on the authentically and typical national beginning throughout the whole chain of the tourist supply.

- Further and significant expansion of the role of information and communication technologies in respect of the demand, planning and realization of trips.

\section{Sector Policy for Development in the Health and Medical Spa Tourism}

One of the main priorities of the European Union in the first decades of the twenty-first century as well as in the future is related to overcome or retention of the impact of negative trends in economical development as result of the aging processes and the increase of socially significant health diseases of the population. Our participation in different scientific forums, analysis of questionnaires and meetings with experts from the sector provided conditions for informal studies and data gathering, concerning the trends in this direction. Results analyses, shared in different reports of leading experts, clients' impressions of the health and medical Spa sector of the tourism and services in Bulgaria and Europe trace out the outlines and the extent of the injuries, caused by the "non-environmentally way of living" on the health and efficiency of different groups of the population.

Increasingly Internet provides access to different data and facts necessary for the analysis of information, gathered for specialized researches. A part of the data, selected for our study, illustrates trends and processes into the dynamic of development of the European and world Health and Medical Spa tourism. This ascertainment is referred to the representatives of the Balkans area countries as well as result of the running economical and socio-political processes. Different industry and professional organizations are working more and more together in quest of generally accepted solutions for health prevention and mostly for handling with the increase of the socially significant health diseases. The Association of Balkan Spa Tourist Organizations works towards synchronization of the informative-explanatory activity for promotion of the product range of health and Spa objects and establishments in all of the member states of this forum. Through the last couple of years, during scientific and practical conferences, held in Albena resort in Bulgaria and Cheshme resort in Turkey, in 2011 and 2012 respectively, were discussed expert reports and visions for common approaches, directed to popularization through more Balkan citizens and guests from other areas of medical treatment by tourist and medical companies specialized in this sector. During the autumn of 2013 in Serbia shall continue the discussion over common projects and initiatives, directed to coordination of the promotionally-advertisement and social policy of the sectors' companies, which supply tourist programmes for local and foreign nationals.

Our authors' visions and forecasts coincide with those of the analysts of different EU states and institutions, who point out that the aging of the enterprises owners and their employees in 
the forthcoming 15-20 years shall affect negatively the European economy in the future, into the frames of globalizing world. According to the United Nations World Tourism Organization /UNWTO/, in 2008 the share of the so called "health tourism" reached $25 \%$ of the total of all types tourist travels.

Of registered within the tourism statistics1000 Spa establishment in Europe, which respond to the classification requirements and cover the Euro-standards annually each is visited on average 33000 times and $39 \%$ of the total number of the general number consumers were visiting such an establishment for first time.

Without an existing official report of turnover in most of the countries of Eastern and Central Europe, annually the spa facilities in Western Europe report in recent years an average of over 360 million US dollars incomes by sales, without considering generally the turnover of the so-called "gray economy" in the business.

The European Spa resorts /including those ones classified by EUROSPA Med included in the European and world statistics of the world travel/ are visited at least once annually by more than 20 million visitors. For these visitors the relaxation or vacation in Spa resort is fairly new form or tourist activity. The most popular forms of the Spa range are the medical, holiday, daily Spa - urban and resort, cosmetic - "beauty" or "cruise" /including visits of Spa centers along the route/. Permanently visited countries, which are developed as Spa destinations in Europe in the beginning of 2011 have establishments with specialized classification of three and more stars. They accomplish activity mainly in the field of Spa, medical Spa and therapeutic hotels activities - Termale and Health hotel. Such destinations are Hungary - 296 establishments, Spain - 128, France - 126, Italy - 114, Turkey - 100, Austria - 81, Greece - 45, Poland - 42, Czech Republic - 34, etc. Bulgaria is not included into the European and world statistical data base, because the respective Bulgarian structures, does not provide information for the above mentioned period.

On this basis the European politicians and economists are looking for an escape from this negative course as well as from a future pessimistic scenario. The commissions and sub-commissions of European Commission as well as those of the European Parliament in Strasbourg discuss and accept into their frames new generally valid decisions. For example new legislative initiatives as regulation of requirements for longer length of service i.e., for increase with 3 up to 5 years of the years required for retirement of present working men and women in the European Union. The objective analysis, as well as the assessment of these initiatives are associated with the unconditional conclusion that only the physically and psychic healthy people could work up to old age. This turns such a social problem into a strategic priority for changes and reason for update of the policies in the field of the public health in the EU Member States.

The disquieting trends of populations' aging in the most developed countries, leads in foreground the issue for the health and the measures for its safeguarding in the context of the development of some new and priority trends of the sector policies of the Union, regarding 
prevention and maintenance of the health status of each citizen in particular. The European Unions' regulations and legislative base are changing annually, towards directions affirming through the priorities of the leading European institutions' policies and support social and health sectors, related to the health prophylaxis of working age people as well as related to the diseases prevention in so called "working urban human". The health prevention leads in foreground the interest of the insurance and health-insurance companies to the programmes and initiatives related to resurgence of the corporative interest to prophylaxis of whole groups of working managerial and executive staff. It should be emphasized the fact, that in the last years a so called medical Spa profile became popular as very fast developing new range in Spa and wellness services supplied in "urban and resort environment". In the end of the first decade of twenty-first century the group and individual consumers of these a programmes in European Union are tens of millions.

Combined like this they become much more popular in the majority of the Northwestern and Central European countries too. The Anglo-Saxon and Scandinavian communities as well the East and Central European countries with developed "resort health culture" included permanently this range in the lists of thousand urban health facilities and resort centers, disposing and using curative mineral waters. The growing image and attractiveness of this type of services are approved annually by "health and beauty" centers, "beauty salons" and studios, fitness clubs and aqua parks, Spa objects at airports and train stations, art cosmetic clubs for VIP customers, centers for beauty and wellness services at cruise ships. The concerns of the thousands Bulgarian investors, managers, experts and academic community representatives in the economical and marketing aspects of this type of specialized services ultimately predetermined the thematic direction of the different sections of the book.

\section{Strategic and Tactical Issues of the Sector Policy in Development of Health and Medical Spa Tourism}

According to Bulgarian and foreign experts, during the forthcoming years, Bulgaria possesses all premises for dynamical and accelerated development of the investment activity to establish functional objects and construct modern, landscaped and easily accessible health and medical Spa resorts. It comes to conduction of coordinated regional policy directed to the territories of more than 60 municipalities, with explored natural resources with health-recreational characteristics.

This economically consistent perspective suggests the sectors' output as a strategic priority, which unconditionally to become as a program part of the different political formations. This requires binding of all competent structures and institutions for elaboration, coordination and accomplishment of strategic and planned national, regional and local policies. Practically, the output as long-term priority of development of the health and medical Spa tourism requires long-term sector and regional policy, which steadily to be supported by the presidential institution as well as by all of the political parties and administrative teams into the frames of the forthcoming planned 5-7 years period. 
The implementation of such national priority is related mainly to elaboration and realization of clear policy aimed to fulfillment of complex forms of state support. This includes mostly new legislative, normative and administrative initiatives, directed to attraction of strategic investments, opening of thousands of new jobs in tourist and health establishments both in the public and private sector as well as in the municipalities and areas with mineral waters with health-recreational characteristics. The main strategic goal is directed to achievement of multifunctional effect at state, regions and local level.

The real economic benefit of implementation of such type marketing-oriented sector or marketing-oriented policies suggests achievement of multi-functional effect, which reflects on the development of the local and regional small and medium sized enterprises, which service the sector. The social effect could be measured as result of the priority implementation of complex of measure $3 \mathrm{~s}$ and actions, which provide raise of welfare and standard of living of the local population. The establishment of sustainable premises and conditions shall guarantee economical upsurge not only to popular resort centers but to dozens new municipalities and regions with registered finds of natural resources with health-recreational characteristics. In particular in the center of these processes lies the reorganization of the balneology or of the physical and rehabilitation medicine in Bulgaria and its transformation into dynamic developing groundwork for health /medical-rehabilitative/ and medical Spa /prophylactic/ tourism. This process already passed into the other European countries with traditions. It includes rationalization and harmonization of the leading strategic or program goals and implementation, of already discussed at all levels, accents of the local, national, economical and social policy in the forthcoming years.

For clarification of the highlights of a long-term sector policy in Bulgaria as priorities, there is a need of political will and concrete program actions for new institutional addressing of the responsibilities and competences at level types of authorities or institutions and professional organizations in the country. There is a need of expert and professional discussion of principles, propositions, stages and measures which shall need concordance and coordination at all possible managerial level to become content for implementation of undivided and far-sighted sector policy of the alternative tourist service in this sphere. In this context, the focus stays change of the attitude of the state to physical medicine and to the balneology as a sector of public health and specialized tourism. These changes include factors and conditions as:

1) The new trends in the Euro-marketing environment, which require change in the emphasis on the use of the hydrothermal resources for psycho-physical prophylaxis, treatment and rehabilitation;

2) The integration of our country into the marketing area of EU in the forthcoming years, which requires new approach to the combined use of the hydrothermal, natural-climatic, cultural-historic, human and other resources for most rational participation in the process of new division of labor in Europe and in the Balkans region; 
3) Establishment of marketing and economical premises, based on the combined use of complex of terms and factors, which are considered as competitive advantages for the country for development of wide range of alternative tourist services;

4) There is a need of actions for regulation and support of the process of internationalization of the health and in particular of the Spa sector through legislative initiatives at national and regional; level. These actions should report on the experience and the achievements of our country and the European countries with high developed medical and Spa tourism sector;

5) Especially important in the long and medium term is the issue of education and training of various categories of executive and managerial personnel for the system. This requires coordinated initiatives and programs implemented together with the competent institutions and schools in the country in the forthcoming years.

The real providers of this type of specialized tourist services are health /health and rehabilitation/ establishments and tourist complexes in urban and resort environment, which are certified or accredited for implementation of this type of specialized tourist activity. These are hospitals, spa and curative hotels, Spa objects and establishments in urban and resort environment, public baths, centers for "Health and beauty", etc. The purpose of such objects and establishments is to offer groups services by conducting regulated and market-oriented prevention programs (prophylaxis), treatment and recovery and relaxation through the use of hot and cold mineral waters and other natural resources.

The users of packages rehabilitation services and spa programs are as chronically diseased or are in different stages of disease cases with patients susceptible to successful spa therapy and rehabilitation and a wide range of users of the spa or wellness tourism programs. According its administrative and sector competency, the Ministry of Health is the state institution which is going to coordinates the implementation of this priority as state policy in the same program period till 2020 at executive level.

On this basis, specific procedures and programs for prevention, treatment and recovery as paid and subsidized healthcare pathways should be developed, approved and offered by the organs and structures related to the performance of the overall health government policy such as the National Health Insurance Fund and the National Insurance Institute (including their representation at national and regional level) for the respective groups of insured population or consumers at home and abroad.

The resource provision for implementation of such priority in the tourist supply in Bulgaria as a policy in the long-term plan is associated with a well-explored and not enough used for spa and spa treatments purposes, physical and other natural healing factors such as:

- Mineral waters and climate;

- Healing mud, peat, sea lye and rap; 
- Herbs and phyto;

- Inhalation substances;

- Bee honey, organic pure food products, etc.

The regional accents of the sector policy in the long-term should be related to improve of the business environment, complex conditions and prerequisites for development of "thermal territories" - municipalities, with the most extensive use of their hydrothermal wealth. This is related to:

1) Linking socio-economic development of the "thermal areas" and communities with the most rational exploitation of hot and cold mineral waters by encouraging investments in facilities and infrastructure in the health and medical Spa tourism;

2) Deep Hydrothermal potential use and development of hydro-energy, greenhouses and other agricultural production, mining of rare minerals and chemicals for pharmaceutical, cosmetics and other effective business trends in these areas;

3) Providing programs with financial resources to maintain ecological balance in the regions, developing a health and Spa tourism and related businesses;

4) Development and implementation of environmental protection activities and programs by the local governments and representatives of national institutions in the regions with rich hydrothermal resources;

5) Obtaining certificates of quality management and compliance with statutory hygiene standards;

6) Use of the conditions for optimal combination of environment and climate, hydrothermal, cultural and historical, infrastructural and human resources to market advantages for dynamic development of spa tourism in the frames of the new market realities of the EU;

7) Development of national criteria for certification trademark of types of mineral water with healing pqualities and how to promote them to the international markets.

The promotion of the competitive advantages of our health and medical Spa tourism in the countries of traditional and new European markets is a responsibility of the authorized state bodies, local governments and tourism enterprises, supplying and offering that range services. The priority actions requiring coordination between the executive and local authorities include:

1) Development of local strategies and development plans of the municipalities (thermal areas) with hydrothermal resources of economic importance including development of health and spa services;

2) Elaboration of National Strategy for development of the regions with hydrothermal potential and programs to support the health and medical Spa tourism at regional level 
with a register of all natural, cultural and historical heritage;

3) Organization within the project initiatives involving or supported by competent state authorities and local governments, including within the framework of public-private partnerships and initiatives and the capacity of expert and consultative groups, research and promotion of successful Bulgarian practices and transfer of European experience. The goals in working on projects funded by the Operational Programmes of research teams on projects are associated with transfer of appropriate technologies and know-how, as well as good cluster and cooperative models such as models and practices. Emphasis should be as common in marketing and promotional activities, training and qualification of personnel or practices for most rational integration of limited natural, human and financial resources in the realization of medium-term planning initiatives at local and regional level, etc.

4) Elaboration of changes in legislative base and regulation of public health and tourism spheres, in particular - Spa (physical and rehabilitation medicine practice) and Medical Spa prophylactic-restorational profile of services for Bulgarian and EU citizens;

5) Conducting sighted and aggressive advertising activity by:

- participation with of common stands, advertising and Internet messages of the resort municipalities and their associations in specialized fairs and exhibitions in Europe and our traditional markets with a focus on the unique advantages of the complex conditions of health and wellness spa tourism;

- coordinated initiatives of NGOs and spa resort communities with support of relevant government departments to promote through thematic working meetings, workshops, seminars and conferences on the healing qualities of waters and environmental and climatic conditions in our resort centers, quality of services and the offered complex product within the four seasons of the year, etc.;

- Internet portals for communications and presentations through Web sites based on well-balanced and diversified advertising campaign funded primarily by the state and tour operators in the country and abroad, etc.

\section{Conclusion}

The following conclusion could be drawn:

- Several studies of Bulgarian and European traditions and modern trends in the forms of exploitation of natural resources and hydrothermal resources assess the priority role and responsibility of local authorities. Municipalities in many countries of the European Union of today, having hydrothermal potential for centuries, define the history and traditions of its use for the benefit of residents and visitors to their sites.

- The changes that should be made in the policy related to the attitude of the municipal government as the direct representative of the interests of the local population in our country 
to large-scaled use of water resources should be linked to the status and their place in European legislation.

- The regulatory framework in Europe is not uniform legislated rights and obligations of the municipalities in the initiation of useful suggestions for the management of hydrothermal resources.

- Common and general criteria and requirements are imposed on the planning process and the statement of the overall EU funding, channelled to support local initiatives such as surveys and feasibility studies of the local natural resources, including water resources and the opportunities for their exploitation.

According to the existing legislation, the Bulgarian municipalities should update periodicallythe Municipal strategies or Development plans for the period to 2020. The funds under the Operational Programmes in the new programming period should be used for the implementation of strategies and plans of the most competitive and discerning local and expert teams working with a clear market orientation. These planned developments should be built or the highlights priorities of the new sector policy in the development of health and Spa facilities of entrepreneurs from home and abroad with new investments in regions and municipalities. It is for those ones with vision and willingness to accept the challenge of our participation in the European division of labor. Like many spa resort municipalities in the Czech Republic, Slovakia, Slovenia and Hungary, now specialized in this area of the tourism market in EU, Bulgarian municipalities possess sufficient potential of underground hot and cold mineral waters, trained local personnel and traditions and should actively participate in the changes. They should be a kind of engine and to initiate renewal of legislative base, including through its local representatives in the Parliament for realization of this long-term socio-economic priority of their municipal or local policy in the next programming period.

\section{Acknowledgement}

The research is financed by Asian Development Bank. No. 2006-A171. Thanks for Prof. AAA BBB, World Technology University.

\section{References}

Carrera, P., \& Lunt, N. (2010). A European perspective on medical tourism: the need for a knowledge base. International Journal of Health Services, 40(3), 469-484. http://dx.doi.org/10.2190/HS.40.3.e

Demunter, C., \& Dimitrakopoulou, C. (2012). Tourism in Europe: Results for 2011.. Statistics in focus, 28, [Online] Available: http://epp.eurostat.ec.europa.eu/cache/ITY_OFFPUB/KS-SF-12-028/EN/KS-SF-12-028-EN

Demunter, C. (2012). Europeans aged 65+ spent a third more on tourism in 2011 compared with 2006. Statistics in focus, 43. [Online] Available: http://epp.eurostat.ec.europa.eu/cache/ITY_OFFPUB/KS-SF-12-043/EN/KS-SF-12-043-EN 


\section{Macrothink}

Green, S. T. (2008), Medical tourism - a potential growth factor in infection medicine and public health. The Journal of infection, 429. http://dx.doi.org/10.1016/j.jinf.2008.09.016

Herrick, D. M. (2007). Medical Tourism: Global Competition in Health Care. National Center for Policy Analysis, NCPA Policy Report No 304. [Online] Available: http://w.medretreat.com/templates/UserFiles/Documents/Medical\%20Tourism\%20-\%20NCP A\%20Report.pdf

Jordanov, J. University of Forestry. (2009). Health and medical spa tourism. Specialized types of tourism (1st ed.), Sofia, Bulgaria, PAL press.

Jordanov, J. University of Forestry. (2007). Marketing in Bulgarian medical spa tourism. Philosophy of successful business (1st ed.), Sofia, Bulgaria, Diana press.

\section{Copyright Disclaimer}

Copyright reserved by the author(s).

This article is an open-access article distributed under the terms and conditions of the Creative Commons Attribution license (http://creativecommons.org/licenses/by/3.0/). 